\title{
Kajian Korosi Struktur Conveyor B pada Tambang Batubara PT XYZ di Kabupaten Merangin Provinsi Jambi
}

\author{
Rizky Yulmansyah* \\ Prodi Teknik Pertambangan, Fakultas Teknik, Universitas Islam Bandung, \\ Indonesia. \\ *rizkyyulmansyah06@gmail.com
}

\begin{abstract}
Conveyor is one of the tools that is used to move excavated materials such as coal. Conveyor structure is made of carbon steel. However, the conveyor structure can experience a decrease in quality due to corrosion that occurs due to direct contact with coal impurities and its environment. This research was conducted on a conveyor structure consisting of 2 segments with 16 test points along 60 meters. This study aims to determine the type of corrosion, corrosion control conditions applied coating. Methodology in this research is measuring the thickness reduction of the conveyor structure. In this study, observations of environmental conditions include an average air temperature of $280 \mathrm{C}$, an average rainfall of $233 \mathrm{~mm}$ and, relative humidity of $87 \%$. The actual thickness measurement of the conveyor structure is using the Ultrasonic Thickness Gauge TT 130. Type of corrosion that occurs in the conveyor structure is uniform corrosion. The corrosion control method applied to the conveyor structure is the coating method. The applied coatings are primer coating using Seaguard 5000, intermediate coating using Sherglass FF and, top coating using Aliphatic Acrylic Modified Polyurethane.
\end{abstract}

Keywords: Conveyor Structures, Carbon Steel and Coating

Abstrak. Conveyor merupakan salah satu alat yang digunakan untuk memindahkan material bahan galian
seperti batubara. Struktur conveyor yang digunakan berbahan dasar baja karbon. Namun demikian struktur
conveyor dapat mengalami penurunan kualitas yang diakibatkan oleh korosi yang terjadi karena kontak
langsung dengan pengotor batubara dan lingkungannya. Penelitian ini dilakukan pada struktur conveyor yang
terdiri dari 2 segmen dengan 16 test point sepanjang 60 meter. Penelitian ini bertujuan untuk mengetahui jenis
korosi, kondisi pengendalian korosi yaitu coating yang diaplikasikan. Metodologi dalam penelitian ini adalah
pengukuran pengurangan ketebalan struktur conveyor. Pada penelitian ini, pengamatan kondisi lingkungan
meliputi temperatur udara rata-rata 280C, curah hujan rata-rata $233 \mathrm{~mm}$ dan kelembapan relatif $87 \%$.
Pengukuran tebal aktual struktur conveyor dilakukan dengan menggunakan alat Ultrasonic Thickness Gauge
TT 130. Jenis korosi yang terjadi pada struktur conveyor yaitu korosi merata. Metode pengendalian korosi
yang diaplikasikan pada struktur conveyor yaitu metode coating. Coating yang digunakan adalah primer
coating menggunakan Seaguard 5000, intermediate coating menggunakan Sherglass FF dan top coating
menggunakan Aliphatic Acrylic Modified Polyurethane.

Kata Kunci: Struktur Conveyor, Baja Karbon dan Coating 


\section{A. Pendahuluan}

Indonesia merupakan negara berkembang yang memiliki bahan galian melimpah, dimana hal tersebut mendorong pertumbuhan industri pertambangan berkembang dengan pesat. Perkembangan tersebut perlu didukung dengan alat transportasi bahan galian yang baik. Oleh karena itu penggunaan conveyor pada industri pertambangan perlu diperhatikan dengan baik sehingga tidak menghambat proses produksi. Conveyor merupakan alat yang digunakan untuk memindahkan material bahan galian.

Struktur conveyor pada umumnya terbuat dari baja karbon. Namun demikian struktur conveyor dapat mengalami penurunan kualitas yang diakibatkan oleh korosi yang terjadi karena kontak langsung dengan pengotor batubara dan lingkungannya. Korosi merupakan kerusakan material yang disebabkan oleh pengaruh lingkungan atau sekelilingnya. Lingkungan sekelilingnya dapat berupa lingkungan asam, udara, embun, air tawar, air laut, air danau, air sungai dan air tanah (Chamberlain, 1991). Korosi mengakibatkan kerusakan terhadap material struktur conveyor sehingga umur pakainya menjadi lebih rendah daripada yang diharapkan.

Monitoring adalah hal yang penting untuk mengontrol korosi yang terjadi, menjaga logam agar tidak mengalami korosi. Kerugian yang ditimbulkan oleh korosi pada conveyor yaitu terjadinya pengurangan ketebalan logam yang dapat menyebabkan conveyor tersebut mengalami patah dan sisa umur pakai conveyor menjadi lebih rendah. Oleh karena itu, diperlukan penelitian ini mengenai kajian korosi pada struktur conveyor agar kegiatan produksi berjalan dengan baik. Adapun tujuan penelitian yaitu:

1. Mengetahui jenis korosi yang terjadi pada struktur conveyor

2. Mengetahui metode pengendalian korosi yaitu coating yang diaplikasikan pada struktur conveyor

\section{B. Metodologi Penelitian}

Batubara adalah salah satu sumber energi. Batubara adalah suatu batuan sedimen (Padatan) yang dapat terbakar, berasal dari tumbuhan, serta berwana cokelat sampai hitam, yang sejak pengendapan terkena proses fisika dan kimia yang menjadikan kaya dengan kandungan karbon. Sedangkan menurut Undang-Undang no 4 tahun 2009 tentang mineral dan batubara, batubara merupakan suatu endapan senyawa organik karbonan yang terbentuk secara alamiah dari sisa tumbuh-tumbuhan dan bisa terbakar. Batubara merupakan salah satu sumber energi memiliki kandungan sulfur di dalamnya. Sulfur telah bergabung dalam sistem pengendapan batubara sejak batubara masih dalam bentuk endapan gambut, sulfur dalam batubara didapatkan dalam bentuk mineral sulfur, mineral sulfida dan mineral organik. Selain itu gambut mengandung semua bentuk sulfur yang didapatkan dalam batubara termasuk sulfur piritik, sulfat dan organik. Kandungan sulfur yang ditemukan pada gambut dapat memperkirakan kuantitas sulfur yang ada dalam batubara. Sumber sulfur pada batubara yang memiliki kandungan sulfur tinggi umumnya berasal dari materia tumbuhan asal dan sulfat air laut yang masuk ke dalam rawa. Kelimpahan sulfur pada batubara sebagian besar dikontrol oleh derajat pengaruh air laut selama akumulasi dan diagenesis. Unsur sulfur terdapat pada batubara dengan kadar bervariasi dari rendah (jauh di bawah 1\%) sampai lebih dari 4\%. Menurut (Kepmen) ESDM Nomor 1395 K/30/MEM/2018 sulfur batubara dikatakan tinggi apabila besar dari 0,8\% dan ash content maksimal yang diperbolehkan sebesar $26,30 \%$. Conveyor adalah salah satu alat angkut yang dapat bekerja secara berkesinambungan (continuos transportasi) baik pada keadaan miring, tegak maupun mendatar.

Baja karbon adalah suatu material logam yang terdiri dari unsur utama besi $(\mathrm{Fe})$ dan unsur kedua karbon (C) yang berpengaruh pada sifat-sifatnya. Adapun beberapa klasifikasi baja karbon yaitu sebagai berikut:

1. Baja karbon rendah (low carbon steel) adalah baja karbon yang mempunyai kandungan utama besi (Fe) dan karbon (C) dengan komposisi karbon sebesar < 0,30\%.

2. Baja karbon sedang (medium carbon steel) adalah baja karbon sedang yang memiliki 
kandungan karbon berkisar $0,30 \%-0,60 \%$.

3. Baja karbon tinggi (high carbon steel) adalah baja yang memiliki kandungan karbon > $0,6 \%$.

Korosi adalah salah satu musuh besar dalam berbagai industri. Kerugian yang ditimbulkan dari korosi adalah terjadinya penurunan kualitas material dan biaya perbaikan yang akan lebih besar dari yang diperkirakan. Untuk menghindari hal tersebut, maka diperlukan pencegahan terhadap serangan korosi. Korosi adalah penurunan kualitas logam yang disebabkan oleh reaksi elektrokimia antara logam dengan lingkungan sekitarnya (Kenneth, R. Trethewey, 1991). Jenis-jenis korosi yaitu korosi merata, korosi sumuran, korosi galvanik, korosi celah dan lain sebagainya.

Metode inspeksi dan pengawasan (monitoring) korosi ialah metode pengukuran pengurangan ketebalan, metode kehilangan berat, dan metode elektrokimia. Korosi yang terjadi pada suatu logam harus dikendalikan agar logam tidak mudah mengalami korosi dan umur pakai logam lebih lama. Beberapa pengendalian korosi (Jones, Denny A., 1996) yang dapat diaplikasikan yaitu seleksi material dan desain, proteksi pelapisan (coating), proteksi katodik dan inhibitor.

Pada dasarnya ketahanan suatu material dalam menghadapi korosi pada kondisi tertentu akan menghasilkan laju korosi (CR) yang berbeda-beda. Berdasarkan laju korosi yang terjadi maka dapat diketahui ketahanan korosi relatif sehingga dapat mempermudah dalam mengetahui kondisi material logam yang sebenarnya. Adapun ketahanan korosi relatif baja dapat digolongkan yaitu outstanding, excellent, good, fair, poor, dan unacceptable. Ketahanan korosi relatif baja dapat dilihat pada Tabel 1.

Tabel 1. Ketahanan Korosi Relatif Baja

\begin{tabular}{|c|c|c|c|c|c|}
\hline $\begin{array}{c}\text { Relative } \\
\begin{array}{c}\text { Corrosion } \\
\text { Resistance }\end{array}\end{array}$ & $\mathrm{Mpy}$ & $\mathrm{mm} / \mathrm{yr}$ & $\mu \mathrm{m} / \mathrm{yr}$ & $\mathrm{Nm} / \mathrm{h}$ & $\mathrm{Pm} / \mathrm{s}$ \\
\hline Outstanding & $<1$ & $<0.02$ & $<25$ & $<2$ & $<1$ \\
\hline Excellent & $1-5$ & $0.02-0.1$ & $25-100$ & $2-10$ & $1-5$ \\
\hline Good & $5-20$ & $0.1-0.5$ & $100-500$ & $10-50$ & $20-50$ \\
\hline Fair & $20-50$ & $0.5-1$ & $500-1,000$ & $50-150$ & $20-50$ \\
\hline Poor & $50-200$ & $0.1-5$ & $1,000-5,000$ & $150-500$ & $50-200$ \\
\hline Unacceptable & $200+$ & $5+$ & $5,000+$ & $500+$ & $200+$ \\
\hline
\end{tabular}

Sumber: Jones, Denny A, 1996

\section{Hasil Penelitian dan Pembahasan}

Jenis material yang digunakan pada struktur conveyor adalah baja ASTM A36 yang memiliki kandungan karbon kurang dari 0,3\%. Berdasarkan kandungan karbon yang dimiliki struktur conveyor ini, maka termasuk jenis baja karbon rendah (low carbon steel). Komposisi kimia material struktur conveyor dari ASTM A36 dapat dilihat pada Tabel 2.

Tabel 2. Komposisi Kimia Material ASTM A36

\begin{tabular}{|l|c|}
\hline \multicolumn{1}{|c|}{ Unsur } & Kadar $(\%)$ \\
\hline Ferrum $\max (\mathrm{Fe})$ & 99,06 \\
\hline Carbon $\max (\mathrm{C})$ & 0,25 \\
\hline Phosphor $\max (\mathrm{P})$ & 0,04 \\
\hline Sulfur $\max (\mathrm{S})$ & 0,05 \\
\hline Silicon $\max (\mathrm{Si})$ & 0,40 \\
\hline
\end{tabular}


Copper $\min (\mathrm{Cu})$

Sumber: ASTM, 2014

Pengukuran ketebalan struktur conveyor dilakukan dengan menggunakan alat Ultrasonic Thickness Gauge TT 130 yang memiliki tujuan untuk mengetahui ketebalan aktual pada struktur conveyor. Pengambilan data ketebalan struktur conveyor dilakukan di 2 segmen dengan 16 test point sepanjang 60 meter. Alat Ultrasonic Thickness Gauge TT 130 dapat dilihat pada Gambar 1.

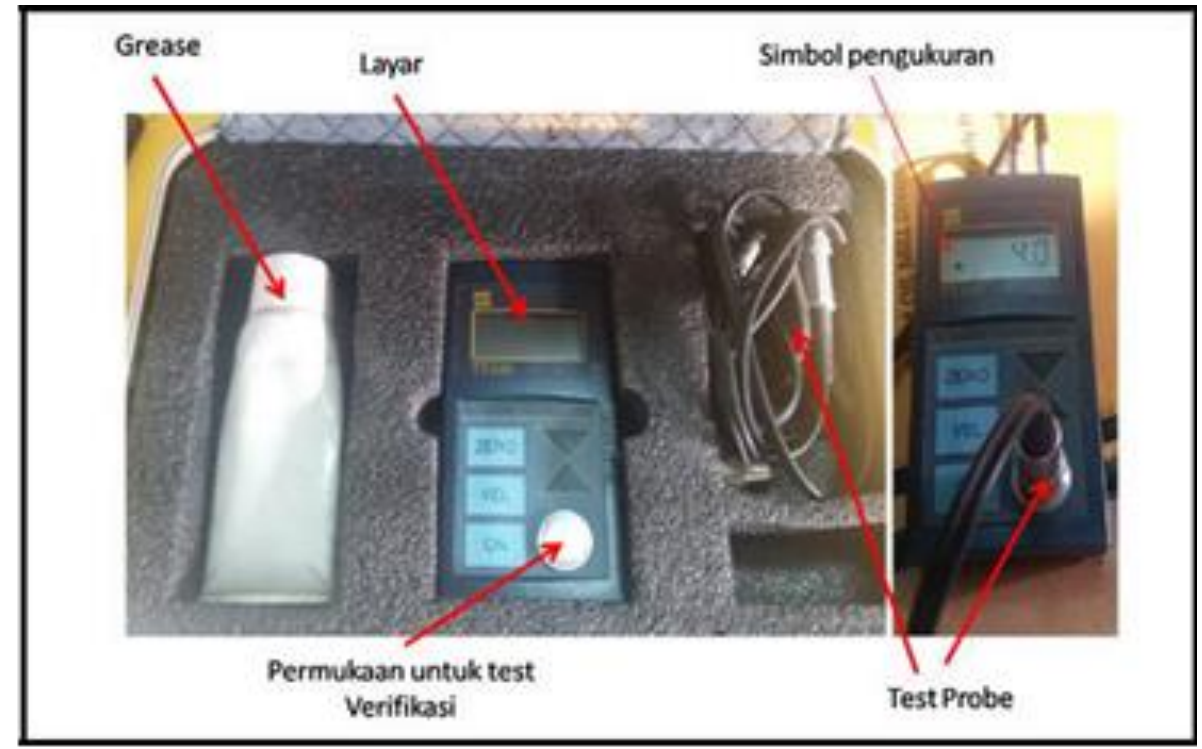

Sumber: Rahmad Azly, 2017

Gambar 1. Ultrasonic Thickness Gauge TT 130

Berdasarkan data pengurangan ketebalan struktur conveyor diketahui jenis korosi yang terjadi adalah korosi merata (uniform corrosion). Hal ini ditandai dengan adanya pengurangan ketebalan struktur conveyor yang terjadi hampir secara merata pada seluruh segmen. Tebal nominal dan tebal aktual struktur conveyor dapat dilihat pada Tabel 3.

Tabel 3. Tebal Nominal dan Tebal Aktual Struktur Conveyor

\begin{tabular}{|c|c|l|c|c|c|}
\hline \multirow{4}{*}{ Segmen Conveyor } & $\begin{array}{c}\text { Test } \\
\text { Point }\end{array}$ & Jenis Struktur & $\begin{array}{c}\text { Tebal } \\
\text { Nominal } \\
(\mathrm{mm})\end{array}$ & $\begin{array}{c}\text { Tebal } \\
\text { Aktual } \\
(\mathrm{mm})\end{array}$ & $\begin{array}{c}\text { Pengurangan } \\
\text { Ketebalan (mm) }\end{array}$ \\
\hline \multirow{4}{*}{ Segmen 1 } & 1 & Support Roller & 11 & 9,29 & 1,71 \\
\cline { 2 - 6 } & & Column & & & \\
\cline { 2 - 6 } & 2 & a. flang & 14,5 & 12,14 & 2,36 \\
\cline { 2 - 6 } & 3 & b. web & 11 & 9,17 & 1,83 \\
\cline { 2 - 6 } & & Girder & & & \\
\cline { 2 - 6 } & 4 & a. flang & 13 & 10,76 & 2,24 \\
\cline { 2 - 6 } & 5 & b. web & 9 & 7,45 & 1,55 \\
\cline { 2 - 6 } & & Support Roller & 11 & 9,24 & 1,76 \\
\cline { 2 - 6 } & & Girder & & & \\
\hline
\end{tabular}




\begin{tabular}{|c|c|c|c|c|c|}
\hline Segmen Conveyor & $\begin{array}{l}\text { Test } \\
\text { Point }\end{array}$ & Jenis Struktur & $\begin{array}{c}\text { Tebal } \\
\text { Nominal } \\
(\mathrm{mm})\end{array}$ & $\begin{array}{c}\text { Tebal } \\
\text { Aktual } \\
(\mathrm{mm})\end{array}$ & $\begin{array}{c}\text { Pengurangan } \\
\text { Ketebalan (mm) }\end{array}$ \\
\hline & 7 & a. flang & 13 & 10,77 & 2,23 \\
\hline & 8 & b. web & 9 & 7,44 & 1,56 \\
\hline \multirow{11}{*}{$\begin{array}{c}\text { Segmen } 2 \\
(31-60 \mathrm{~m})\end{array}$} & & Girder & & & \\
\hline & 9 & a. flang & 13 & 10,76 & 2,24 \\
\hline & 10 & b. web & 9 & 7,48 & 1,52 \\
\hline & 11 & Support Roller & 11 & 9,24 & 1,76 \\
\hline & & Girder & & & \\
\hline & 12 & a. flang & 13 & 10,67 & 2,33 \\
\hline & 13 & b. web & 9 & 7,45 & 1,55 \\
\hline & & Girder & & & \\
\hline & 14 & a. flang & 13 & 10,76 & 2,24 \\
\hline & 15 & b. web & 9 & 7,44 & 1,56 \\
\hline & 16 & Bracing & 12,5 & 10,22 & 2,28 \\
\hline
\end{tabular}

Berdasarkan data tebal nominal dan data tebal aktual dapat dilihat terjadi pengurangan ketebalan struktur conveyor berkisar antara 1,52 mm sampai dengan 2,36 $\mathrm{mm}$ yang menunjukkan bahwa jenis korosi yang terjadi yaitu korosi merata (uniform corrosion). Hal ini ditandai dengan adanya pengurangan ketebalan struktur conveyor yang terjadi hampir secara merata di seluruh test point struktur conveyor. Korosi merata (uniform corrosion) dapat terjadi dimanapun apabila ada air dan oksigen serta dapat disebabkan juga oleh adanya kontak secara terus menerus antara permukaan struktur conveyor dengan lingkungannya.

Metode pengendalian korosi yang diaplikasikan pada struktur conveyor ini dilakukan secara eksternal. Pengendalian korosi untuk mencegah terjadinya korosi secara eksternal dilakukan dengan menggunakan metoda coating yang terdiri dari primer coating menggunakan Seaguard 5000 yang berfungsi sebagai base coat atau lapisan dasar, Intermediate coating menggunakan Sherglass $F F$ yang berguna sebagai lapisan kedua yang bertujuan untuk lapisan menjadi kedap air dan untuk menciptakan tebal lapisan tertentu dan top coating menggunakan Aliphatic acrylic modified polyurethane yang berfungsi untuk pelindung paling luar yang mampu tahan terhadap kondisi lingkungan.

1. Primer Coating

Primer coating yang digunakan yaitu Seaguard 5000. Jenis coating ini memiliki daya rekat yang baik dan anti korosi untuk diaplikasikan pada baja, selain itu sesuai untuk temperatur udara $2,8^{\circ} \mathrm{C}-43^{\circ} \mathrm{C}$ dengan nilai kelembaban relatif maksimum $85 \%$. Seaguard 5000 dapat dilihat pada Gambar 2. 


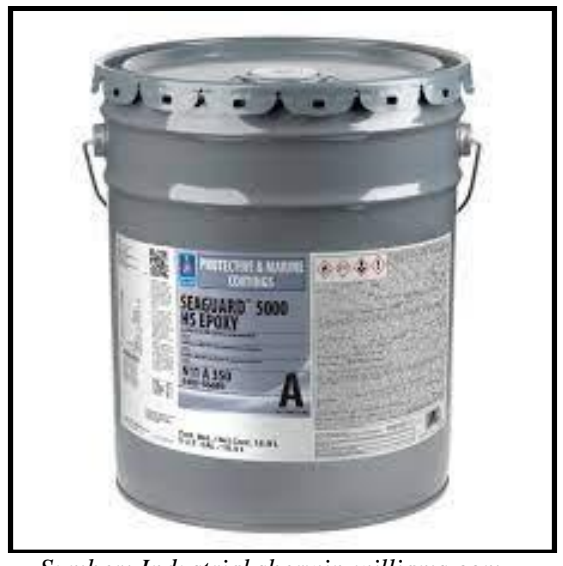

Sumber: Industrial.sherwin-williams.com

Gambar 2. Primer Coating Seaguard 5000

2. Intermediate Coating

Intermediate coating menggunakan Sherglass FF. Jenis coating ini dapat melindungi baja dari korosi, tahan akan benturan dan tahan abrasi. Pengeras standar udara dan bahan pada permukaan temperatur udara minimum $13 \mathrm{oC}$ dan maksimum $49 \mathrm{oC}$. Sherglass FF dapat dilihat pada Gambar 3.

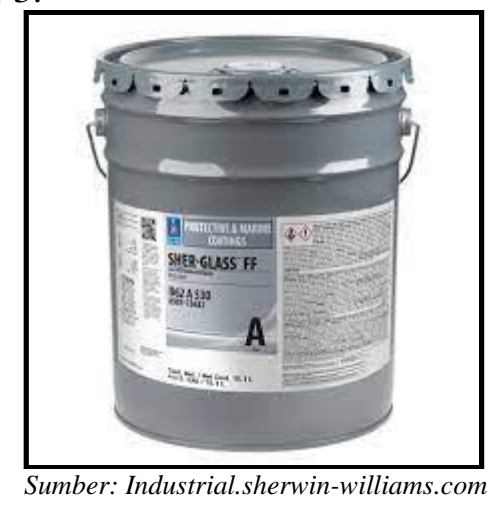

Gambar 3. Intermediate Coating Sherglass FF

\section{Top Coating}

Top coating yang digunakan adalah Aliphatic acrylic modified polyurethane. Jenis coating ini adalah modifikasi akrilik alifatik dua komponen dengan VOC rendah yang dirancang khusus untuk melapisi lapisan akhir pada baja. Jenis coating ini sesuai untuk temperatur udara $4,5 \mathrm{oC}-49 \mathrm{oC}$ dengan nilai kelembaban relatif maksimum $85 \%$. Aliphatic acrylic modified polyurethane dapat dilihat pada Gambar 4. 


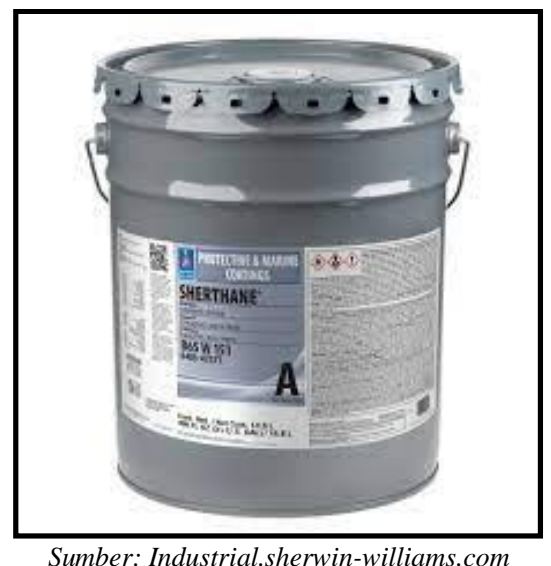

Gambar 4. Top Coating Aliphatic acrylic modified polyurethane

\section{Kesimpulan}

Berdasarkan hasil penelitian ini, maka dapat disimpulkan sebagai berikut:

1. Jenis korosi yang terjadi pada struktur conveyor adalah korosi merata (uniform corrosion).

2. Metode pengendalian korosi yang digunakan pada struktur conveyor adalah metode coating yaitu primer coating menggunakan Seaguard 5000, Intermediate coating menggunakan Sherglass $F F$ dan top coating menggunakan Aliphatic acrylic modified polyurethane.

\section{Daftar Pustaka}

[1] Arif, Irwandy, 2014,"Batubara Indonesia". Gramedia Pustaka Utama, Jakarta.

[2] Anonim, 1993, "Properties and Selection: Irons, Steels, and High Performance Alloys". ASM Handbook Committee, United States.

[3] Anonim, 2002,"Belt Conveyor For Bulk Material". Conveyor Equipment Manufacturers Association, United States.

[4] Baihaqi, Ray Adam, Prstikno, Herman, dan Hadiwidodo, Yoyok Setyo, 2019, “Analisis Sour Corrosion Pada Baja ASTM A36 Akibat Pengaruh Asam Sulfat Dengan Variasi Temperatur dan Waktu Perendaman Di Lingkungan Laut", Jurnal Teknik, ISSN : 2337 3539, Institut Teknologi Sepuluh Nopember, Surabaya.

[5] Chou, C.L. 2012,"Sulfur in Coal: A Review Of Geochemistry And Origins". International Journal of Coal Geolog.

[6] Daryanto dan Amanto, 2006.“Ilmu Bahan” Bumi Aksara, Jakarta.

[7] Farid, Faizar. 2011. "Adsorpsi batubara terhadap ion timbal". Sainmatika: Jurnal Sains dan Matematika Universitas Jambi.

[8] Hunafa, Irham, Moralista, Elfida, dan Pramusanto, 2018, "Penentuan Laju Korosi dan Sisa Umur Pakai (Reamining Service Life/RSL) Discharge Convetor Di PT Genesa Korosi Indonesia Pada Site PT Amman Mineral Nusa Tenggara, Kabupaten Sumbawa Barat, Provisi Nusa Tenggaea Barat", Prosiding Teknik Pertambangan, ISSN: 2460-6499, Universitas Islam Bandung, Bandung.

[9] Jones, A, Denny J, 1996, "Principle and Prevention of Corrosion" Prentice Hall, New Jersey.

[10] Kenneth,R. Trethewey, 1991."Korosi untuk Mahasiswa Sains dan Rekayasa” Gramedia Pustaka Utama, Jakarta.

[11] Marlina A, Riam, dan Rahmalina, Annisa, 2019, "Pengaruh Air Laut Terhadap Pengurangan Kadar Sulfur Pada Batubara Sub-bituminus", Jurnal Sains dan Teknologi, ISSN: 2615- 
2827, Sekolah Tinggi Teknologi Industri Padang, Padang.

[12] Projosumarto, Partanto, 1993 ."Pemindahan Tanah Mekanis” Institut Teknologi Bandung, Bandung.

[13] Santoso, Binarko. 2015. "Petrologi Batubara Sumatra dan Kalimantan: Jenis, Peringkat dan Aplikasi”. LIPI. Jakarta

[14] Supriyanto, 2007."Pengaruh Konsentrasi Larutan $\mathrm{NaCl}$ 2\% dan 3,5\% terhadap Laju Korosi Pada Baja Karbon Rendah” Universitas Muhammadiyah Surakarta, Surakarta.

[15] Trethewey, KR dan Chamberlain, J. 1991."Korosi Untuk Mahasiswa dan Rekayasawan" PT Gramedia Pustaka Utama. Jakarta.

[16] Utomo, Budi, 2019."Jenis Korosi dan Penanggulangannya” Universitas Diponegoro, Semarang. 